International Journal of Heritage, Tourism and Hospitality Vol. (12), No. (2/2), September, 2018 By: Faculty of Tourism and Hotels, Fayoum University, Egypt

\title{
Evaluation of Current Smart Airport Technologies Implemented in Cairo International Airport
}

Mahmoud M. O. Mohamed Hala Ahmed Gomaa Nashwa Samir El-Sherif Faculty of Tourism and Hotel Management Helwan University

\begin{abstract}
The implementation of smart technologies is no longer a feature of sophisticated airports but an important tool in today's aviation industry. The current research aims at evaluating the extent to which smart airport technologies are implemented in Egyptian Airports with particular focus on Cairo International Airport through the collection and analysis of both primary and secondary data. The primary phase is merely qualitative and depends on both observation and interviewing techniques. The interviews were in-depth semi-structured and were conducted with four key representatives of the Egyptian airport sector. The paper highlights several constraints that hinder the adequate implementation of smart tools and technologies in Cairo International Airport and presents recommendations on how to overcome such constraints.
\end{abstract}

Key words: Cairo International Airport, E-gates, Self-service Check-in Points, Smart Technologies.

\section{Introduction to smart airports}

The "Smart airport" is a term that refers to the intelligent infrastructure of an airport. It is derived from the concept of "Smart cities", "Smart building", and "factories of the future". The global smart airport infrastructure is classified into endpoint devices that include communication systems, passenger, cargo, and baggage handling, air traffic control systems, security systems, and others. Endpoint devices are further segmented into sensors, tags, IP phones, and video conferencing (Chesher, 2013).

According the Société Internationale de Télécommunications Aéronautiques (SITA) the Smart Airport is an airport which leverages the convergence of three trends: passenger self-service, mobility and collaborative decision-making to create a smart predictive environment for the most effective flow of passengers and goods through an airport, both during normal operation as well as during times of disruption (SITA, 2016).

The global smart airport market is dominated by key players including IBM Corporation, Cisco, and Siemens AG, while other players such as Raytheon, Amadeus IT Group, and QinetiQ are identified as emerging players in the market. Players such as Honeywell and SITA are amongst the promising players in the smart airport market with a strong position and relatively median growth as compared to the market leaders (Angelakis, 2017).

Leading players are currently focusing on integrating products to create a new customer base. As a part of this strategy, they are engaging in strategic partnerships and acquisitions. 
Figure 1: Smart Airport Vision

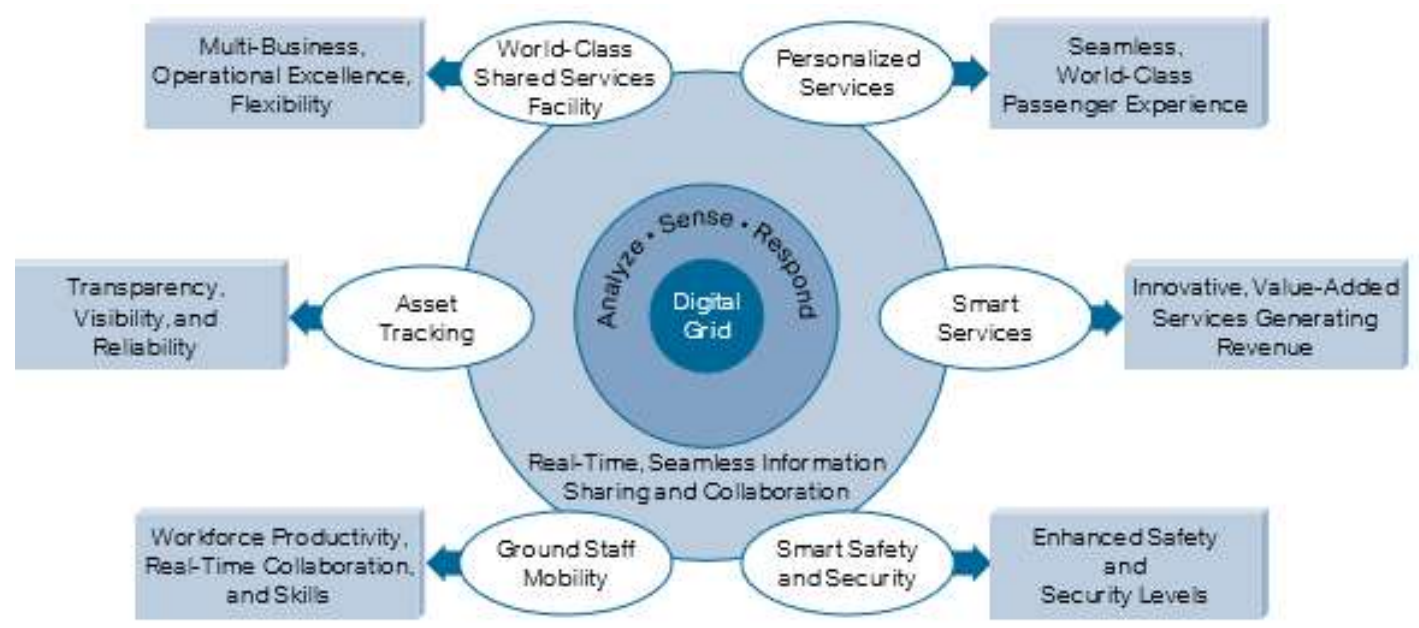

Source: CISCO, 2009.

\section{Literature Review}

\section{Examples of smart airport tools and technologies}

E-gates: the smart gates or e-gates electronically check the biometric authenticity of a passport and check that the holder's facial features match those contained on the passport's electronic chip. The passenger is allowed to exit the gate once the machine gives the green light. The e-gates are aimed at speeding up the movement of passengers as a single immigration officer can monitor several e-gates at the same time. Thus, facilitating shorter queuing times is achieved. E-Gates contribute greatly to the enhancement of the immigration controls including border security while at the same time they contribute to the provision of an improved passenger experience through self-service and speedier passage through which the immigration process is attained (Budd, 2017).

The Self-Service Check-in: the use of self-service kiosks has become a permanent common fixture in airport terminals across Europe over the last few years. Passengers show an increasing willingness to use online and mobile technology to check-in for their flight and retrieve their boarding pass. In the U.K, a new generation of kiosk has emerged. This has been led by British Airways, which has introduced kiosks that not only allow passengers to check-in, select their seat and print their boarding pass, but also print out and attach their own baggage tags for checked luggage. This means that checked bags can simply be deposited at a bag drop counter upon arrival at the airport. Combined with the ability to check-in online before arriving at the airport, the kiosks are designed to give the passenger more control over their journey and ease congestion in the terminal (Heathrow Express, 2015).

Airport Mobile Application: The Airport mobile app provides the information required by passengers right at their fingertips, with travel planning tools, terminal information, news, special offers and everything passengers need for an easy journey to and through the airport. Among the features of such app. are: Getting live flight updates with a new tracker service, making journeys easier with travel notifications and prompts, planning journeys with connections' planner, booking long stay parking, seeing the latest offers in shops and restaurants, and viewing maps of the terminal (Hirsh, 2016). 


\section{Best Practice Models of Smart Airports}

The following part gives examples of three international airports: Hartsfield-Jackson International Airport in Atlanta (USA), Heathrow Airport in London (UK) and Dubai International Airport in Dubai (DXB) that are known to have best practices in the implementation of smart technology in the airline industry.

Hartsfield-Jackson International Airport in Atlanta (USA) is an airport with 22 smart lanes at security checkpoints, completing the full roll-out of the new lanes, aimed at speeding the screening process. The roll-out of the smart lanes started in 2016, as one of the efforts exerted to address long security lines that contact Hartsfield-Jackson and airports across the country. Hartsfield-Jackson International Airport was the first airport in the United States that was developed to test the new smart lanes. The airport was funded with a $\$ 1$ million investment by Atlanta-based Delta Air Lines for the first two lanes (fig. 2) and another $\$ 12.5$ million paid for by the airport for an additional 20 lanes (Euring, 2017). Additionally, Jackson International Airport encompasses other smart technologies such as Fingerprints (Birkner, 2017). Meanwhile, Automated Boarding Gates are being examined (Delta, 2017).

Figure 2: Delta Air Lines e-gates

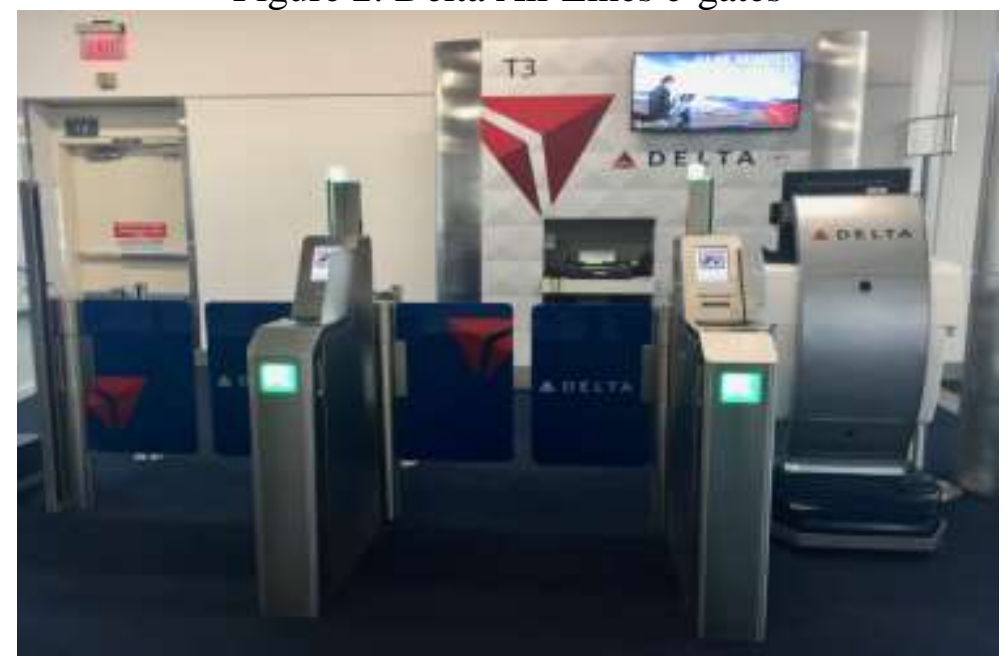

Source: Delta Air Lines, 2018.

Since Hartsfield-Jackson launched the smart lanes, other airports and airlines have begun installing them around the country. The smart lane setup keeps slower passengers from holding up the line, by allowing five passengers to load bins at the same time. The security lane can handle 160 people per hour, while the smart lane can handle up to 208 passengers per hour during busy holiday periods. This decreases the waiting period from 35 minutes to less than 20 minutes, which is considered the airport's goal (Blatt, 2017).

Heathrow Airport's Positive Boarding project uses smart data tracking to improve departures punctuality and improve the passenger experience. Technology experts from Heathrow and its project partner Atkins explain how the system works, and how it fits into the airport's growing array of data and biometrics innovations. The most recent departures innovation being rolled out by Heathrow is Positive Boarding, a passenger-friendly method of improving flight punctuality, which was recently shortlisted as a nominee for Airport Industry Review's Innovation in Passenger Services Technology Award. The scheme, which has now been introduced for Virgin Atlantic flights from Terminal 3, as well as United Airlines and Little Red departures from Terminal 1, leverages and expands the airport's existing data management software to improve passenger information and reduce the chance of tardy travellers 
holding up flights by not reaching their boarding gate on time (Airbank, 2017). Moreover, the Smart Screen Technology and the High-Tech Mirror are also examples of smart tools applied in Heathrow Airport (NEC, 2017).

Figure 3: Heathrow Airport Smart Boarding System

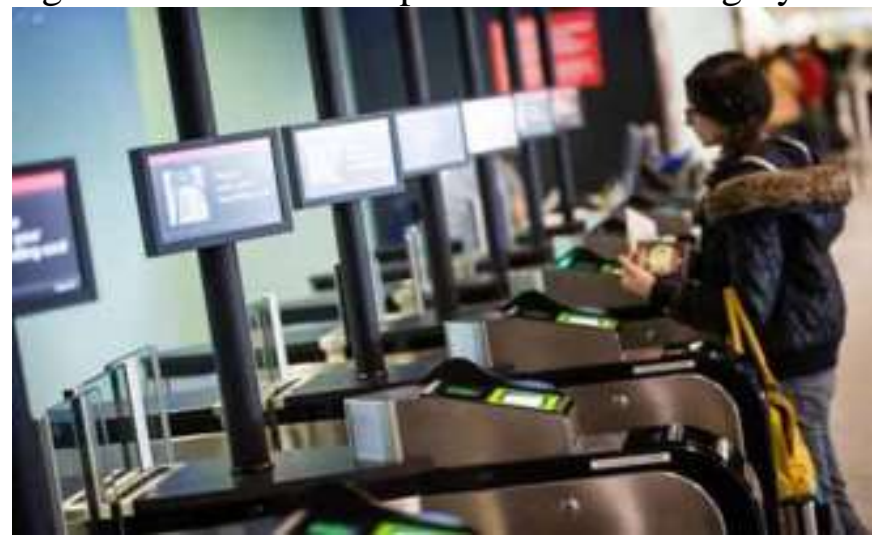

Source: Air bank, 2017.

The system starts with a 'ticket presentation point', a row of automated entry gates just before the security area, where passengers scan their standard boarding passes on their way to security. Individual passengers are identified through the data on their boarding pass barcodes, and the data is collated alongside central flight information. The system then verifies that the passengers are entering the right terminal for their flight and work out on how much time they have to reach their boarding gate. Based on this information, messages are sent both to the passenger and the relevant airline. In this way, passengers can be kept informed of any time issues for boarding their flight, and airlines can make use of a more detailed passenger manifest to monitor their flights as they begin to fill up. If the flight is actually boarding and some passengers are running a bit late, they will get a friendly message saying 'Flight boarding from gate 22 ', for instance. Thus, firstly they know they need to get down to the gate once they are through security process, and secondly they do not have to try and find out which gate they are going from, as they have been told that in advance (Mirror, 2017).

Dubai International Airport is the primary international airport serving Dubai, United Arab Emirates and it is regarded the third busiest airport in the world by passenger traffic, the sixth busiest cargo airport in world, the busiest airport for Airbus A380 and Boeing 777 movements, and the busiest airport in the world operating with only two runways. In 2016, the airport handled 83.6 million passengers, 2.59 million tonnes of cargo and registered 418,220 aircraft movements (IATA, 2017).

Moreover, passenger wait times at Dubai International Airport have dropped by as much as ten per cent during the first quarter of 2017 due to the implementation of new technologies at the world's busiest airport for international passenger traffic. Recent results show that in the first three months of 2017, 84 per cent of transfer passengers were processed within five minutes, 68 per cent of arrival passengers were processed within 15 minutes, and 87 per cent of departing passengers were processed within 10 minutes (IATA, 2017).

Now, passengers do not even need to take passport out of bag to get through immigration. Instead of scanning their passport to pass through the e-gates, now all they need is smart phone. Smart UAE Wallet, the new service allows passengers flying on Emirates out of Dubai International Airport's Terminal three to simply tap their phone to the screen instead of procuring a travel document such as a passport or 
Emirates ID. The Smart U.A.E Wallet is an app that can be downloaded, and when passengers open the app, it will contain basic passenger information and flight details, and a bar code will be scanned at the e-gate terminals (Gulf News, 2017). Additionally, a big range of digital tools are applied in Dubai International Airport including Smart Gates (Dnrd, 2017) and Sophisticated Motion Sensor Systems (Bright, 2017).

\section{Research aim}

The research aims to explore the extent to which Cairo International Airport implements smart airport technologies with particular focus on investigating perceptions regarding the feasibility of employing any of the smart airport tools implemented in the best practice models presented in the study.

\section{Research methodology}

The research implemented an exploratory qualitative approach aiming at identifying the smart airport technologies in Cairo International Airport through the collection of both secondary and primary data. The secondary data was gathered from previous relevant studies and publications whereas, the collection of the primary data depended on both personal observation and in depth semi-structured interviews with four key representatives in the airport sector and the field of aviation industry in Egypt. The positions of the interviewees are as follows: Head of Cairo Airport Insurance Investigation, Head of the State Security Bureau at the airport, Head of Egypt Air Technical Office, and Former president of the Egyptian aviation authority. The interviewees were particularly selected to participate in this study due to their long experience, extended knowledge and professional background in the field of investigation at the operational level.

In this regard, the personal observation has taken place to experience the airport environment in a real-life situation and to monitor the available smart tools in the airport - if any - while the semi-structured interviews encompassed a number of questions that were directed to the interviewees leading to the emergence of new ideas in the area under investigation (Lee, 2009). The interviews took place in June 2018. Each interview lasted for almost an hour. The interviews enabled the collection of rich qualitative data around the following themes; exploration of smart airport technologies in Cairo International Airport, and the potentiality of adopting the smart technologies in the Egyptian airports.

\section{Results and discussion}

\section{First: Cairo International Airport overview}

Cairo International Airport is the biggest airport in Egypt and one of the biggest in Africa, with the capacity to serve about 30 million passengers per year, and is the second busiest airport in Africa, with many flights operating between the east and west connecting Cairo with the world. For this reason, flights to Cairo airport are available from many cities in North America, Europe, Africa and Asia. The airport is located nine miles $(15 \mathrm{~km})$ outside of Cairo. The facilities at Cairo International Airport are good, especially in Terminal 3, which has more than 5,000 square feet of retail space and a food court. The terminals are spread out over two miles $(3 \mathrm{~km})$ apart, so passengers should allow time for the shuttle ride when transferring (World bank, 2013). Nevertheless, upon reviewing the wide range of smart airport technologies identified earlier, it was intended to explore the extent to which smart airport technologies are implemented in Cairo International Airport being the biggest and 
busiest airport in Egypt. In this respect, examples of smart airport tools implemented in the three international airports - referred to earlier - were depicted and compared to the smart technologies available in Cairo International Airport based on the information gathered from the interviews and personal observation (table 1).

Table 1: A comparison between smart airport technologies in Cairo International Airport and Dubai, Hartsfield Jackson and Heathrow International Airports

\begin{tabular}{|l|c|c|c|c|}
\hline \multirow{2}{*}{$\begin{array}{l}\text { Smart Airport } \\
\text { Tools }\end{array}$} & $\begin{array}{c}\text { Airports } \\
\text { International } \\
\text { Airport }\end{array}$ & $\begin{array}{c}\text { Dubai } \\
\text { International } \\
\text { Airport }\end{array}$ & $\begin{array}{c}\text { Hartsfield- } \\
\text { Jackson } \\
\text { International } \\
\text { Airport }\end{array}$ & $\begin{array}{c}\text { Heathrow } \\
\text { Airport }\end{array}$ \\
\hline Smart Wallets & & $*$ & $*$ & $*$ \\
\hline Smart Lanes & & & $*$ & $*$ \\
\hline Positive Boarding & & & & $*$ \\
\hline Finger print & $*$ & & & $*$ \\
\hline Smart screen & & & & $*$ \\
\hline High-Tech mirror & $*$ & & & \\
\hline Smart gates ( E-gates) & $*$ & & & \\
\hline $\begin{array}{l}\text { Sophisticated motion } \\
\text { sensor systems }\end{array}$ & & & & \\
\hline Self-check-in points & $*$ & & & \\
\hline $\begin{array}{l}\text { Airport } \\
\text { applications }\end{array}$ & & & & \\
\hline
\end{tabular}

\section{Second: Analysis of interview questions}

Theme 1: Exploration of current smart airport technologies in Cairo International Airport

Central to smart airport technologies implemented in Cairo International Airport, the interviewees reported the following:

1-Self-services Check-in Points, have been installed in Cairo International Airport for the first time in Terminal 3 in 2008 then it has been installed in Terminal 2 in 2015. However, they are used by a limited number of passengers due to the fact that many citizens are still not acquainted enough with the system. Moreover, some of these Check-in Points went out of service due to technical problems. This is supported by a photo that has been taken in Terminal 2 in 2018 which shows a message on the screen reporting that the kiosk is temporary out of service and that passengers are requested to contact their airline for assistance, whereas, another message on the top screen indicates that the service is being developed and will be available soon. 
Figure 4: Self-service Check-in point Cairo International Airport

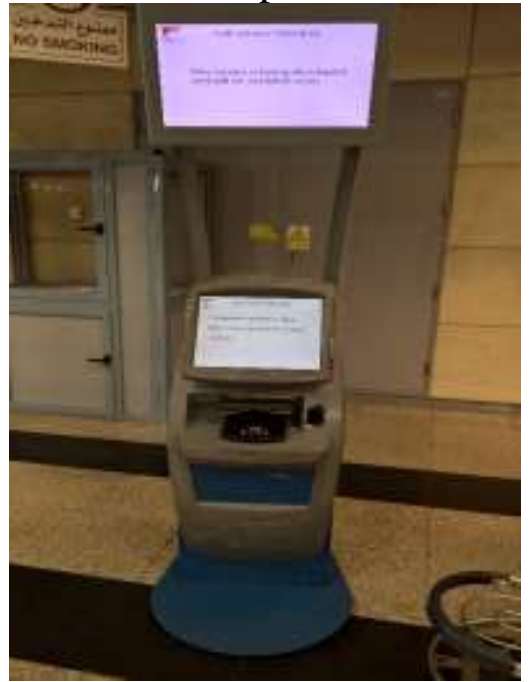

Source: Cairo International Airport Terminal 2

2- In 2015, E-gates have been installed in Cairo International Airport, two gates in each terminal. However, the use of such gates has not achieved the goals set by the airport authorities due to the fact that passengers rarely tended to use them. This has been referred to the fact that the use of this service was eligible only for Egyptian citizens, with an annual fee of 3000 Egyptian Pounds and requires a series of complicated procedures to obtain the smart ID that enables the passenger to go through including for instance: a full security check, the males' army service status, criminal records, etc. This is also supported by photos taken in Terminal 2 in 2018 through personal observation (fig.5)

Figure 5: The e-gates at Cairo International Airport in Terminal 2

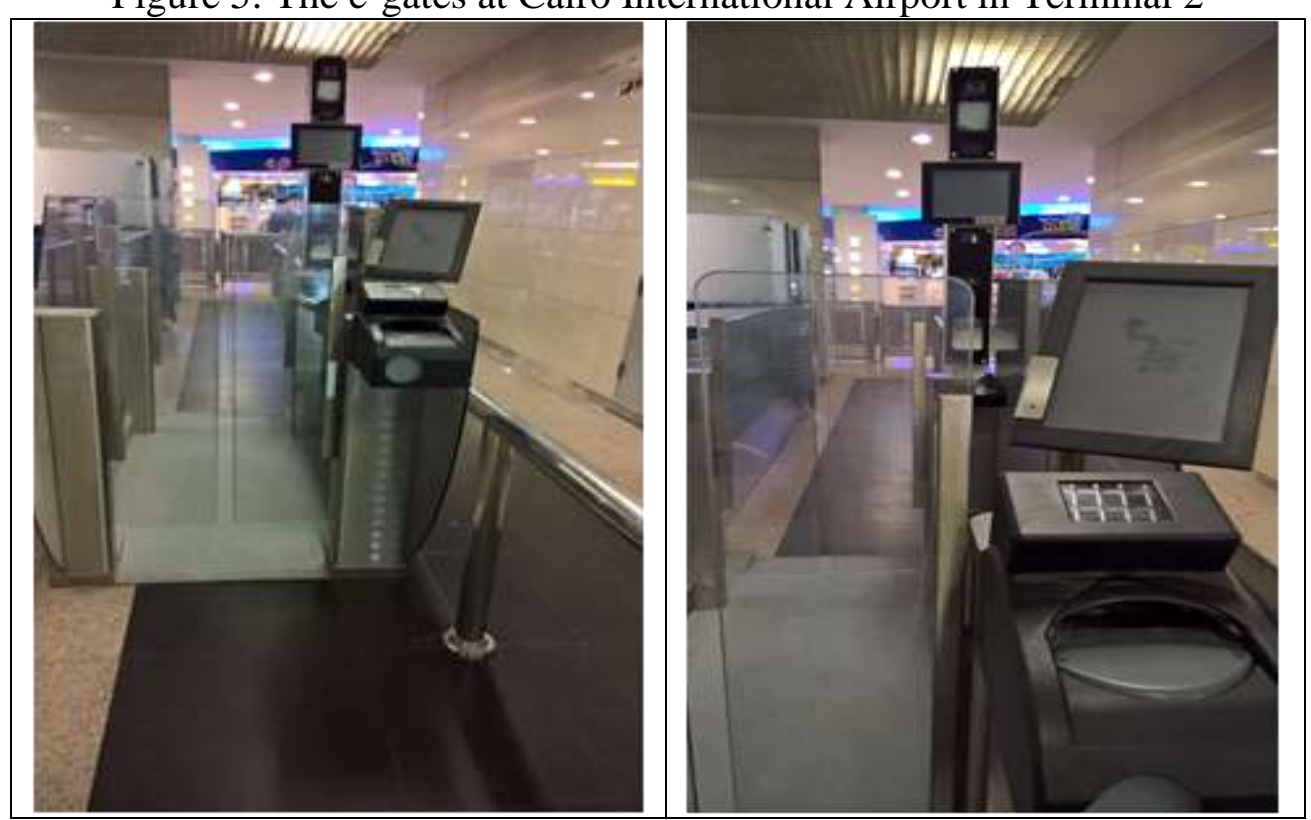

Source Cairo International Airport Terminal 2 service

3- Cairo Airport Mobile Application has been implemented in 2012. Nevertheless, not all of the passengers are aware of it. Moreover, the app does not provide users with all required information (i.e. schedules of train and bus services, notifications for flight delays, map of the airport terminals and their amenities such as cafés, restaurants and duty free shops, etc.). The following figure demonstrates such app. 
International Journal of Heritage, Tourism and Hospitality Vol. (12), No. (2/2), September, 2018 By: Faculty of Tourism and Hotels, Fayoum University, Egypt

Figure 6: Cairo Airport Mobile Application

\begin{tabular}{|c|c|c|c|}
\hline Carrier $₹$ & 1:10 AM & $\begin{array}{l}\text { AM } \\
\text { arch }\end{array}$ & 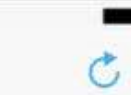 \\
\hline Filter & All & Arrivals & Departures \\
\hline
\end{tabular}

Flight number

Date

\begin{tabular}{|l|l|l|}
\hline By Airline & By City & By Airport \\
\hline
\end{tabular}

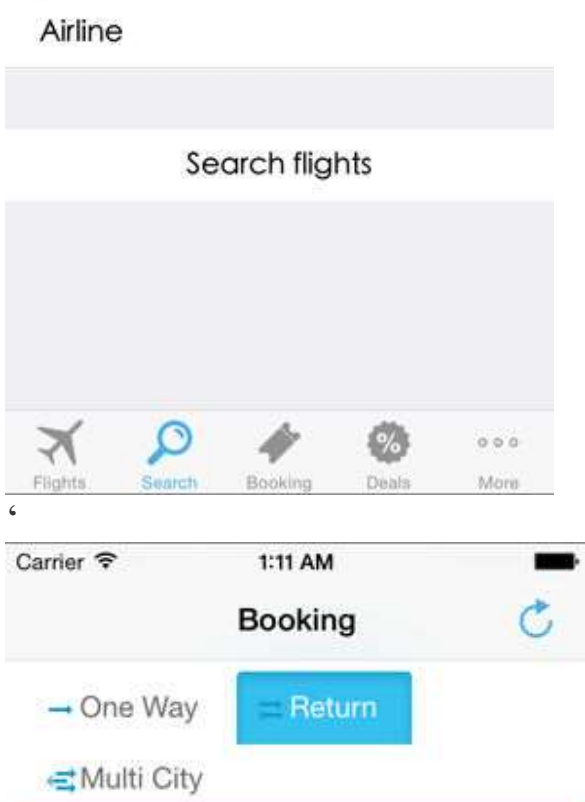

\section{More information}

\section{Jeddah, King Abdulaziz Internationai Airport}

\section{Arrived 3 hrs. 26 mins ago (Early: 56} mins)

Pin this flight
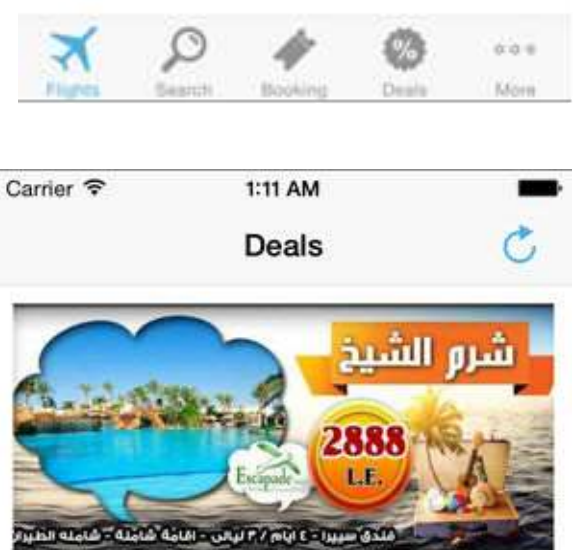

Sharm EISheikh 4 Days / 3 Nights .. Full Board, Including Flight Tickets

Sharm EISheikh 4 Days TravelYalla

2,888 EGP
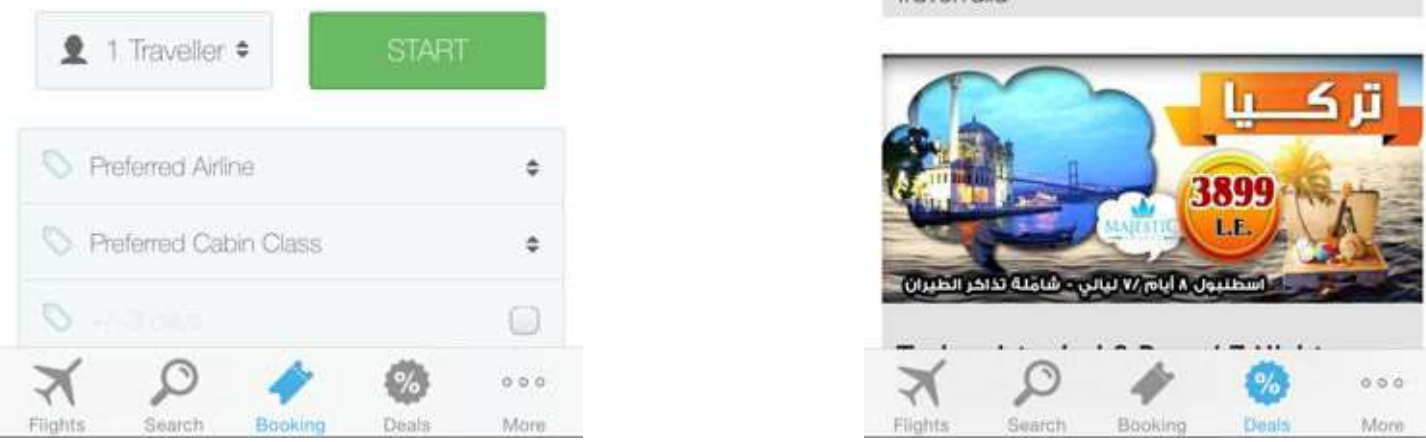

Source: Air bank, 2017.

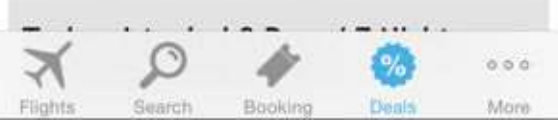

In this regard, SITA (2017) agreed that using smart airport technologies will be the only way to improve the quality of passenger services. These technologies will work together to provide passengers with enhanced experiences at the airport through realtime alerts, notifications and promotions and the use of multiple technologies in order to create a seamless experience. 
Theme 2: Possibility of adopting smart airport technologies in Egyptian airports

The interviewees were asked about the factors affecting the airport technologies in the Egyptian airports. Central to this question; all of the interviewees agreed that the implementation of smart airport technologies in the Egyptian airports will contribute much to the competence of such airports in the future. They also reported that the adoption of such technologies requires clear vision and a well-designed plan that is to be set and implemented not only by the Egyptian Airport Authorities but also by the other various stakeholders including private sector investors concerned with the airline industry.

The interviewees recommended that Cairo International Airport should be the first airport in Egypt to implement smart technologies as it constitutes a part of the country's image being Egypt's main airport that receives thousands of passengers a day. Others agreed that the development of such a technology should be oriented towards airports with smaller capacities, as it would be easier to implement, being of lower cost investment, particularly that they receive international passengers who are familiar with smart airport technologies. In this respect, Sharm El Sheikh International Airport, Hurghada International Airport, Marsa Alam International Airport, and Luxor International Airport were recommended. The interviewees also indicated that the implementation of the smart airport tools and technologies should neither be very fast nor very slow in order to guarantee a safe transition on one hand and to maintain the airport's market share on the other hand adding that employing the smart airport technology in Egyptian airports is expected to meet the needs of future generations.

In this concern, Cooper et al. (2015) indicated that national governments should actively participate in the development of smart airport systems in two different ways: First, they can participate as an operator, focusing on air traffic control services, transportation systems, security, baggage handling and screening, customs and immigration.

Second, they can participate as a regulator with regulations applying to airport infrastructure and service providers within airport systems.

\section{Conclusion}

The research discussed the concept of smart airport technologies identifying some of the tools and best practices in this respect with particular emphasis on the various benefits that passengers as well as airport authorities gain from airport smart technologies such as e-gates, self-check-in kiosks, and airport mobile applications that highly contribute to the smooth flow of passengers in international airports particularly busy ones that receive thousands of passengers a day such as Cairo International Airport. The current research also shed light on the main constraints that hinder the proper implementation of the smart airport model in Egypt with particular focus on the procedures that should be taken in this respect particularly the governmental ones. The research also revealed debatable opinions regarding whether the implementation of smart airport technologies should take place in Cairo International Airport or in any of the other smaller International airports across Egypt which is one of the issues that should be put into consideration by airport authorities and stakeholders prior to setting plans for development in the aviation sector. additionally, it has been indicated that adequate maintenance is always required to make the best use of the airport's smart technologies otherwise the return on investment in such technologies will be unfeasible. 


\section{Recommendations}

A number of recommendations have emerged from the current research, among which are the following:

- It is recommended that Cairo Airport Company raises the awareness of the use of smart technologies among passengers through the airport's website, printed materials handed to passengers as well as human assistance.

- It is also recommended that Cairo Airport Company seeks establishing sustainable partnerships with both public and private sector companies. Such collaboration will help in allocating more funds for the development of smart airport tools within the airport premises so as to meet the requirements of the global airline industry on one hand and to fulfil the customers' satisfaction and loyalty on the other hand.

\section{References}

Angelakis, V., Tragos, E., Pöhls , H, C., 2017. Designing, Developing, and Facilitating Smart Cities. Springer. Sweden.

Airbank, 2017. Heathrow Airport Launches Smart Boarding System. Available at: http://www.airbank-travel.com/heathrow-airport-boarding-system. [Accessed on 20 July 2017]

Birkner, C., 2017. How Delta's Focus on Customer Experience Turned. Available at: http://www.adweek.com/brand-marketing/how-deltas-focus-on-customerexperience-created-a-powerhouse-brand [Accessed on11 April 2017]

Blatt, S., 2017. Hartsfield-Jackson Atlanta International Airport 2016 Annual Report. Available at: http://www.atl.com/atl-releases-2016-annual-report. [Accessed on 25 Dec 2017]

Bright, C., 2017. Dubai Airports Plans "smart tunnel" passport checks.

Available at: http:// www.businesstraveller.com/business-travel/2017/10/09/dubaiairports-plans-smart-tunnels-passport-checks/ [Accessed on 18 Nov 2017]

Budd, L. and Ison, S., 2017. Air Transport Management: An international perspective. Routledge. New York.

Chesher, M., Kaura, R. and Linton, P., 2013. Electronic Business and Commerce. Second Edition. Springer, London.

Cooper, R.; Aouad, G.; Lee, A.; Wu, S.; Fleming, A. and Kagioglou, M., 2015. Process Management in Design and Construction, Blackwell Publishing, New Jercy.

CISCO, 2017. Smart Airports: Transforming Passenger Experience To Thrive in the New Economy. Available at: https://www.cisco.com. (Accessed on 2 May 2018)

Delta Airlines, 2017. Delta unveils redesigned gate and boarding experience. Available at: https://news.delta.com. [Accessed on 2 May 2018]

Dnrd, 2017. Smart Gates. Available at: http://dnrd.ae:8080/en/Services/Pages/Smartgate.aspx.aspx. (Accessed on 2 May 2017).

Euring, E., 2017. SMART AIRPORT -STRUCTURE AND ELEMENTS. Available at: http://www.agir.ro/buletine/2812.pdf. [Accessed on 1 DEC 2017]

Gulf News, 2017. Smartphone is your passport in Dubai. Available at: http://gulfnews.com/news/uae/emergencies/now-smartphone-is-your-passport-indubai-1.2040149. [Accessed on 18 Jan 2017]

Heathrow Express, 2015. Smart screens at Heathrow compare live airport transfer options. Available at: https://www.heathrowexpress.com/news/corporate-newspr/2015/04/20/world-first-smart-screens-at-heathrow-compare-live-airporttransfer-options. [Accessed on 2 Jun 2017] 
Hirsh, M., 2016. Airport Urbanism: Infrastructure and Mobility in Asia. University of Minnesota Press, Minnesota, United States.

IATA, 2017. Airport of The Future. Available at: https://www.iata.org/whatwedo/ops-infra/airportinfrastructure/Documents/AoF_brochure_02.pdf. [Accessed on 30 AUG 2017].

Lee, I., 2009. Electronic Business: Concept, Methodologies, Tools, and Applications. U.S.A. Information Science Reference.

Mirror., 2017. Heathrow T5. Available at: http://www.mirror.co.uk/news/uknews/heathrow-t5-light-bulbs-fail-2847774 2015. [Accessed on 22 Jan 2017]

NEC, 2017. Smart airport supports your smooth travel. Available at: http://www.nec.com/en/global/onlinetv/en/society/airport.html. [ Accessed on 14 March 2017]

SITA, 2016. Smart Airport of The Future Planning for Innovation at Airports. Available at: https://www.sita.aero/globalassets/docs/events/2016-south-africainnovation-day/4-sita-jnb-innovation-day-aug-16-innovation.pdf. [Accessed on14 AUG 2017]

SITA, 2017. Smart technology for a hassle-free passenger journey Available at: http://www.sita.aero/resources/type/infographics/smart-technology-for-smarterairports. [Accessed on 1 NOV 2017]

World Bank, 2013. Egypt - Airport Development Project. Available at: http://documents.worldbank.org/curated/en/637611468744274929/CairoInternational-Airport-terminal-3-building-and-new-runway. [Accessed on $14 \mathrm{Sep}$ 2017] 